\title{
Second-line treatment strategy for urothelial cancer patients who progress or are unfit for cisplatin therapy: a network meta-analysis
}

Huitao Wang, Jianhe Liu* ${ }^{*}$, Kewei Fang, Changxing Ke, Yongming Jiang, Guang Wang, Tongxin Yang,

Tao Chen and Xin Shi

\begin{abstract}
Background: Second-line treatment for urothelial carcinoma (UC) patients is used if progression or failure after platinum-based chemotherapy occurs or if patients are cisplatin-unfit. However, there is still no widely accepted treatment strategy. We aimed to analyze the effectiveness and safety of second-line treatment strategies for UC patients.

Methods: The PubMed, Embase, and Cochrane databases were searched for randomized controlled trials (RCTs) that included UC patients who were cisplatin-ineligible or unfit up to April 19, 2019. The primary outcomes were progression-free survival (PFS), overall survival (OS), and objective response rate (ORR).

Results: Thirteen trials that assessed 3502 UC patients were included. This study divided the network comparisons into three parts. The first part contained studies comparing taxanes and other interventions; the second part assessed investigator's choice chemotherapy (ICC)-related comparisons; and the third part assessed best support care (BSC). In the OS results of the first part, pembrolizumab (87.5\%), ramucirumab plus docetaxel (74.6\%), and atezolizumab (71.1\%) had a relative advantage. Pembrolizumab also had advantages in ORR and severe adverse effect (SAE) results. Vinflunine and ramucirumab plus docetaxel had a relatively high surface under the cumulative ranking curve (SUCRA) rank by exploratory cluster analysis.
\end{abstract}

Conclusions: This study concluded that atezolizumab and pembrolizumab are superior to other treatments, mainly in OS results, but no treatment confers a significant advantage in PFS. Pembrolizumab still has relative advantages in ORR and SAE results compared to ICC. Due to limitations, more studies are necessary to confirm the conclusions.

Keywords: Urothelial carcinoma, Cisplatin-ineligible, Second-line, Meta-analysis

\section{Introduction}

Urothelial carcinoma (UC) is the most common cancer of the bladder and upper urinary tract and is invasive and lethal, especially in advanced and metastatic patients $[1,2]$. Advanced UC (AUC) patients generally have a poor prognosis, and only a few patients survive more than 5 years [3]. Platinum-based first-line chemotherapy is a standard treatment for muscle-invasive UC (MIUC)

\footnotetext{
* Correspondence: liujh1109@yeah.net

Department of Urology, The Second Affiliated Hospital of Kunming Medical

University, No.374, Dianmian Avenue, Yunnan 650101, People's Republic of China
}

(c) The Author(s). 2019 Open Access This article is distributed under the terms of the Creative Commons Attribution 4.0 International License (http://creativecommons.org/licenses/by/4.0/), which permits unrestricted use, distribution, and

and AUC patients and mainly includes gemcitabine plus cisplatin (GC) and methotrexate, vinblastine, doxorubicin, and cisplatin (MVAC) regimens $[4,5]$.

Although many patients have an initial objective response when they first receive platinum-based chemotherapy, some patients still have disease progression. For those patients, second-line treatment is then used [6, 7]. There is also a group of patients who are unfit for cisplatin treatment; the most common cause is renal insufficiency or neurological disease $[8,9]$. For those patients, carboplatin-based treatment is usually applied. There are many types of second-line treatment for cisplatin- 
progression or unfit UC patients at present, including vinflunine, taxanes, checkpoint inhibitors, antiangiogenic therapy, etc. However, there is still no widely accepted treatment strategy.

Previous meta-analyses showed that immunotherapy can significantly improve UC patients' overall survival (OS) compared with chemotherapy, while antiangiogenic drugs combined with chemotherapy did not significantly improve patients' progression-free survival (PFS) and OS compared to chemotherapy alone. Taxanes and vinflunine treatment had similar effects but different side effects $[10,11]$. A meta-analysis analyzed the efficacy of single and double chemotherapeutic drugs as secondline treatments. Although dual-drug combinations can improve the objective response rate (ORR) and PFS, they had no obvious benefit for OS [12]. This study will analyze the safety and effectiveness of second-line treatment strategies for UC patients with cisplatin progression or who are unfit for cisplatin by network metaanalysis to provide guidance for clinical treatment.

\section{Methods}

This network meta-analysis was reported in line with the preferred reporting items for systematic reviews and meta-analyses (PRISMA) and the PRISMA extension statement for network meta-analysis [13].

\section{Data sources and searches}

To identify studies for inclusion in this review, we searched the following public databases: PubMed, Embase, and the Cochrane Central Register of Controlled Trials up to April 19, 2019. The search terms used in the search strategy included ((()bladder OR intravesical OR urothelial OR urethral OR urothelium OR urinary)) AND (neoplasms OR cancer OR malignant OR carcinoma OR tumor)) AND (random* OR randomized OR randomised)) AND (cisplatin OR platin OR platinum OR carboplatin). Only English-language articles were considered. The search strategy is detailed in the supplementary materials (Additional file 4: Table S1). The references of related reviews were also checked to avoid omissions.

\section{Study selection}

Two authors independently selected the literature. In the case of any disagreements, a third author was introduced for discussion to reach a consensus. The inclusion criteria are as follows: 1, randomized controlled trials (RCTs); 2, studies that included UC patients who were cisplatin-resistant or unfit for cisplatin; 3, comparative studies on cytotoxicity therapy or immunotherapy; and 4, the outcome evaluation included one of the following: PFS, OS, and ORR. The exclusion criteria were as follows: 1 , studies that compared the different doses or usage of the same drugs; and 2, studies that did not report one of the main outcomes (PFS, OS, or ORR). Conference abstracts, posters, and presentations of ongoing RCTs were also excluded because these brief reports do not contain detailed safety data.

\section{Data extraction}

Data extraction was performed at the study level but not at the individual level. The extraction contents included the following: author name, publication year, research location, sample size, age of patients, stage of disease, progression or unfit status after cisplatin, intervention treatment, control, outcome report, and follow-up period. The primary results included PFS, OS, and ORR results. The secondary results included severe adverse effects (SAEs) according to the National Cancer Institute (NCI) Common Terminology Criteria $>=$ grade 3. The Cochrane Collaboration method, which includes seven specified domains, was used to assess the methodological quality of the included trials [14].

\section{Data synthesis and statistical analysis}

We used a frequentist framework, random-effects model for mixed multiple treatment comparisons. Network plots were produced for interventions and comparisons, and the node in each plot indicates the intervention regimen, while the line indicates each direct comparison [15]. We used odd ratios (ORs) and their 95\% confidence intervals $(\mathrm{Cls})$ to quantify the frequency of events results in the network meta-analysis, such as ORR and SAE results. Hazard ratios (HRs) and their 95\% Cls were used to quantify the PFS and OS Cox regression results. The global inconsistency of the network analysis was evaluated by the fitness of the consistency model and the inconsistency model. Local inconsistency was assessed by the closed loops in the network for differences between direct and indirect comparisons. The surface under the cumulative ranking curve (SUCRA) probabilities were used to rank the treatments for each outcome [16]. Comparison-adjusted funnel plots were used to determine small-study effects in the analysis [17]. The SUCRA scores of all results were clustered by the average linkage clustering method to avoid the interference of individual deviation results on the overall results. A traditional meta-analysis was used to compare the interventions that could not be assessed by network meta-analysis. Data analyses were performed using STATA software (version 14.0; STATA Corporation, College Station, TX, USA).

\section{Results}

\section{Literature search}

The database searches yielded 1426 potentially relevant studies after the removal of duplications. A total of 1390 
articles were excluded after screening the titles and abstracts. The full texts of the remaining 36 articles were assessed. Studies were excluded due to the following reasons: non-RCTs (9); conference abstracts (4); studies comparing the same intervention drugs (3); studies not analyzing cisplatin-progression or unfit patients (3); reviews (2); and duplicated publications (2) (Fig. 1). Finally, thirteen articles were included for further analysis [18-30].
In the included studies, 3502 cisplatin-progression or unfit UC patients were analyzed. The studies were all published after 2011. Two studies were located in the UK and France, while others were multicenter studies [22, 30]. All studies included AUC or metastatic UC patients. Two studies reported the results of the same population at different follow-up periods [18, 31], and this study combined the above two results (Table 1). All

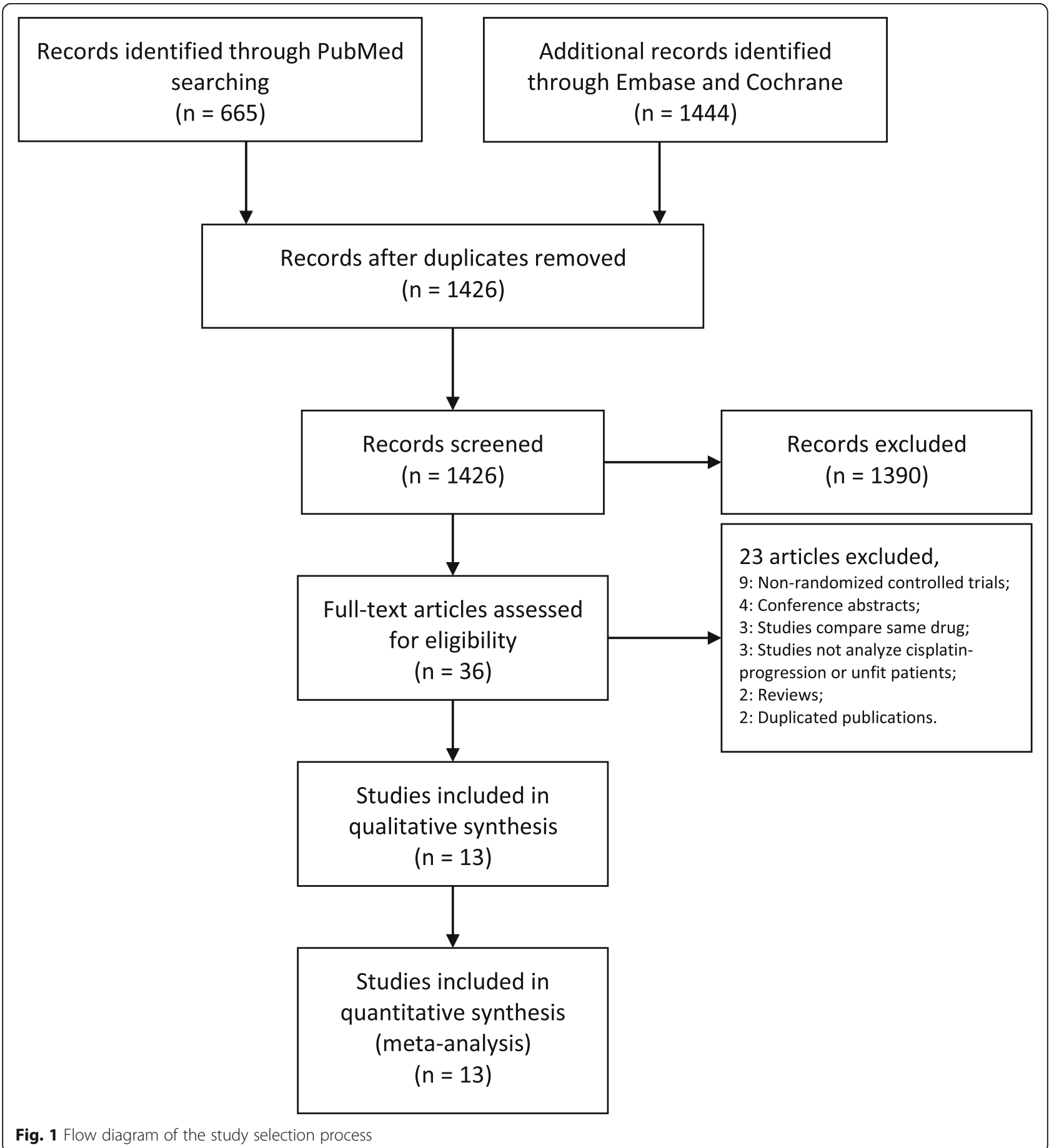


the studies were performed with a randomization design. Three studies were performed with a blindness design to reduce the impact of subjective awareness on the outcomes. Overall, the quality of the included studies was ideal (Fig. 2).

This study divided network comparisons into three parts. The first part contained studies comparing taxanes and other interventions, and the interventions included apatorsen plus docetaxel, icrucumab plus docetaxel, pazopanib, ramucirumab plus docetaxel, taxane, vandetanib plus docetaxel, and vinflunine. The second part contained studies comparing investigator's choice chemotherapy (ICC) and others, and interventions included atezolizumab, ICC, and pembrolizumab. The last part contained studies comparing best support care
(BSC) and others, including personalized peptide vaccination (PPV) plus BSC, BSC, and vinflunine plus BSC. In the OS results, two ICC-related articles reported subgroup results according to different chemotherapy regimens $[18,20]$, so pembrolizumab and atezolizumab were also included in the OS results of the first part of the network analysis.

The first part of the taxane-related network analysis included PFS, OS, ORR and SAE results. Among the PFS results, there were six comparisons on taxane, among which the comparison of ramucirumab plus docetaxel and taxane was the most accurate (Fig. 3a). However, there were no significant differences among the network comparisons. Vinflunine and ramucirumab plus docetaxel ranked higher in the SUCRA results (Table 2).

Table 1 Characteristic of included studies

\begin{tabular}{|c|c|c|c|c|c|c|c|c|c|c|c|}
\hline Author & Year & Location & $\begin{array}{l}\text { Sample } \\
\text { size }\end{array}$ & $\begin{array}{l}\text { Title of } \\
\text { research }\end{array}$ & $\mathrm{Age}^{\mathrm{a}}$ & $\begin{array}{l}\text { Stage of } \\
\text { disease }\end{array}$ & $\begin{array}{l}\text { Reason of } \\
\text { second-line } \\
\text { therapy }\end{array}$ & Intervention & Control & Outcome & $\begin{array}{l}\text { Follow- } \\
u^{b}\end{array}$ \\
\hline $\begin{array}{l}\text { Fradet Y [18] } \\
\text { supplementa }\end{array}$ & 2019 & Multicentre & 542 & $\begin{array}{l}\text { KEYNOTE- } \\
045\end{array}$ & $\begin{array}{l}65(26- \\
86)\end{array}$ & Advanced & Progression & Pembrolizumab & ICC & $\begin{array}{l}\text { OS;PFS; } \\
\text { ORR;AE }\end{array}$ & Open \\
\hline $\begin{array}{l}\text { Rosenberg } \\
\text { [19] }\end{array}$ & 2018 & Multicentre & 200 & Borealis-2 & $\begin{array}{l}67(35- \\
92)\end{array}$ & Metastatic & Progression & $\begin{array}{l}\text { Docetaxel plus } \\
\text { Apatorsen }\end{array}$ & Docetaxel & $\begin{array}{l}\text { OS:PFS; } \\
\text { ORR;AE }\end{array}$ & Open \\
\hline $\begin{array}{l}\text { Powles T } \\
\text { [20] }\end{array}$ & 2018 & Multicentre & 931 & IMvigor211 & $\begin{array}{l}67(31- \\
88)\end{array}$ & $\begin{array}{l}\text { Advanced } \\
\text { or } \\
\text { metastatic }\end{array}$ & Progression & Atezolizumab & ICC & $\begin{array}{l}\text { OS;PFS; } \\
\text { ORR;AE }\end{array}$ & Open \\
\hline $\begin{array}{l}\text { Petrylak DP } \\
{[21]}\end{array}$ & 2017 & Multicentre & 530 & RANGE & $\begin{array}{l}66(32- \\
86)\end{array}$ & $\begin{array}{l}\text { Advanced } \\
\text { or } \\
\text { metastatic }\end{array}$ & Progression & $\begin{array}{l}\text { Docetaxel plus } \\
\text { ramucirumab }\end{array}$ & $\begin{array}{l}\text { Docetaxel } \\
\text { placebo }\end{array}$ & $\begin{array}{l}\text { PFS;ORR; } \\
A E\end{array}$ & Open \\
\hline Jones RJ [22] & 2017 & UK & 131 & NA & $\begin{array}{l}69(61- \\
77)\end{array}$ & $\begin{array}{l}\text { Advanced } \\
\text { or } \\
\text { metastatic }\end{array}$ & Progression & Pazopanib & Paclitaxel & $\begin{array}{l}\text { OS;PFS; } \\
\text { AE;QOLS }\end{array}$ & Open \\
\hline $\begin{array}{l}\text { Bellmunt J } \\
\text { [23] }\end{array}$ & 2017 & Multicentre & 70 & SECAVIN & $\begin{array}{l}63(35- \\
80)\end{array}$ & Advanced & Failure & Cabazitaxel & Vinflunine & $\begin{array}{l}\text { ORR;PFS; } \\
\text { OS }\end{array}$ & Open \\
\hline $\begin{array}{l}\text { Petrylak DP } \\
{[24]}\end{array}$ & 2016 & Multicentre & 148 & NA & $\begin{array}{l}66(29- \\
85)\end{array}$ & $\begin{array}{l}\text { Advanced } \\
\text { or } \\
\text { metastatic }\end{array}$ & Progression & $\begin{array}{l}\text { Docetaxel plus } \\
\text { ramucirumab }\end{array}$ & $\begin{array}{l}\text { Docetaxel plus } \\
\text { icrucumab }\end{array}$ & $\begin{array}{l}\text { PFS;OS; } \\
\text { ORR;SAE }\end{array}$ & Open \\
\hline $\begin{array}{l}\text { Santis MD } \\
{[25]}\end{array}$ & 2016 & Multicentre & 69 & JASINT1 & $\begin{array}{l}72(42- \\
79)\end{array}$ & Advanced & Unfit & $\begin{array}{l}\text { Vinflunine; } \\
\text { Gemcitabine }\end{array}$ & $\begin{array}{l}\text { Vinflunine; } \\
\text { Carboplatin }\end{array}$ & $\begin{array}{l}\text { PFS;OS; } \\
\text { SAE;ORR }\end{array}$ & $\begin{array}{l}25.9 \\
M(24.3- \\
26.5)\end{array}$ \\
\hline $\begin{array}{l}\text { Noguchi M } \\
{[26]}\end{array}$ & 2015 & Multicentre & 80 & NA & $\begin{array}{l}\text { 65(46- } \\
84)\end{array}$ & Advanced & Progression & PPV plus BSC & $\mathrm{BSC}$ & $\begin{array}{l}\text { PFS;OS; } \\
\text { SAE }\end{array}$ & $36 \mathrm{M}$ \\
\hline $\begin{array}{l}\text { Bellmunt J } \\
{[27]}\end{array}$ & 2012 & Multicentre & 370 & NA & NA & Advanced & Failure & Vinflunine;BSC & $\mathrm{BSC}$ & $\begin{array}{l}\text { OS;PFS; } \\
\text { ORR;SAE }\end{array}$ & $\begin{array}{l}21.5 \\
M(16.7- \\
25.3)\end{array}$ \\
\hline $\begin{array}{l}\text { Choueiri TK } \\
{[28]}\end{array}$ & 2012 & Multicentre & 149 & NA & NA & $\begin{array}{l}\text { Advanced } \\
\text { or } \\
\text { metastatic }\end{array}$ & Progression & $\begin{array}{l}\text { Docetaxel; } \\
\text { vandetanib }\end{array}$ & $\begin{array}{l}\text { Docetaxel; } \\
\text { placebo }\end{array}$ & $\begin{array}{l}\text { PFS;OS; } \\
\text { SAE;ORR }\end{array}$ & Open \\
\hline $\begin{array}{l}\text { Santis MD } \\
{[29]}\end{array}$ & 2011 & Multicentre & 238 & $\begin{array}{l}\text { EORTC } \\
\text { Study 30, } \\
986\end{array}$ & $\begin{array}{l}71(34- \\
87)\end{array}$ & Advanced & Unfit & $\begin{array}{l}\text { Gemcitabine; } \\
\text { carboplatin }\end{array}$ & $\begin{array}{l}\text { Methotrexate; } \\
\text { carboplatin; } \\
\text { vinblastine }\end{array}$ & $\begin{array}{l}\text { OS;PFS; } \\
\text { ORR;SAE }\end{array}$ & Open \\
\hline $\begin{array}{l}\text { Culine } \\
\text { Stephane } \\
\text { [30] }\end{array}$ & 2011 & Frence & 44 & $\begin{array}{l}\text { GETUG } \\
\text { V01 }\end{array}$ & $\begin{array}{l}76(48- \\
86)\end{array}$ & Advanced & Unfit & Gemcitabine & $\begin{array}{l}\text { Gemcitabine; } \\
\text { oxaliplatin }\end{array}$ & $\begin{array}{l}\text { ORR;OS; } \\
\text { SAE }\end{array}$ & Open \\
\hline
\end{tabular}

BSC Best support care, ICC investigator's choice chemotherapy, NA not available PPV personalized peptide vaccination ${ }^{a}$ Median (minimum-maximum)

${ }^{b}$ Open: follow-up until disease progress or patient death; M: months 


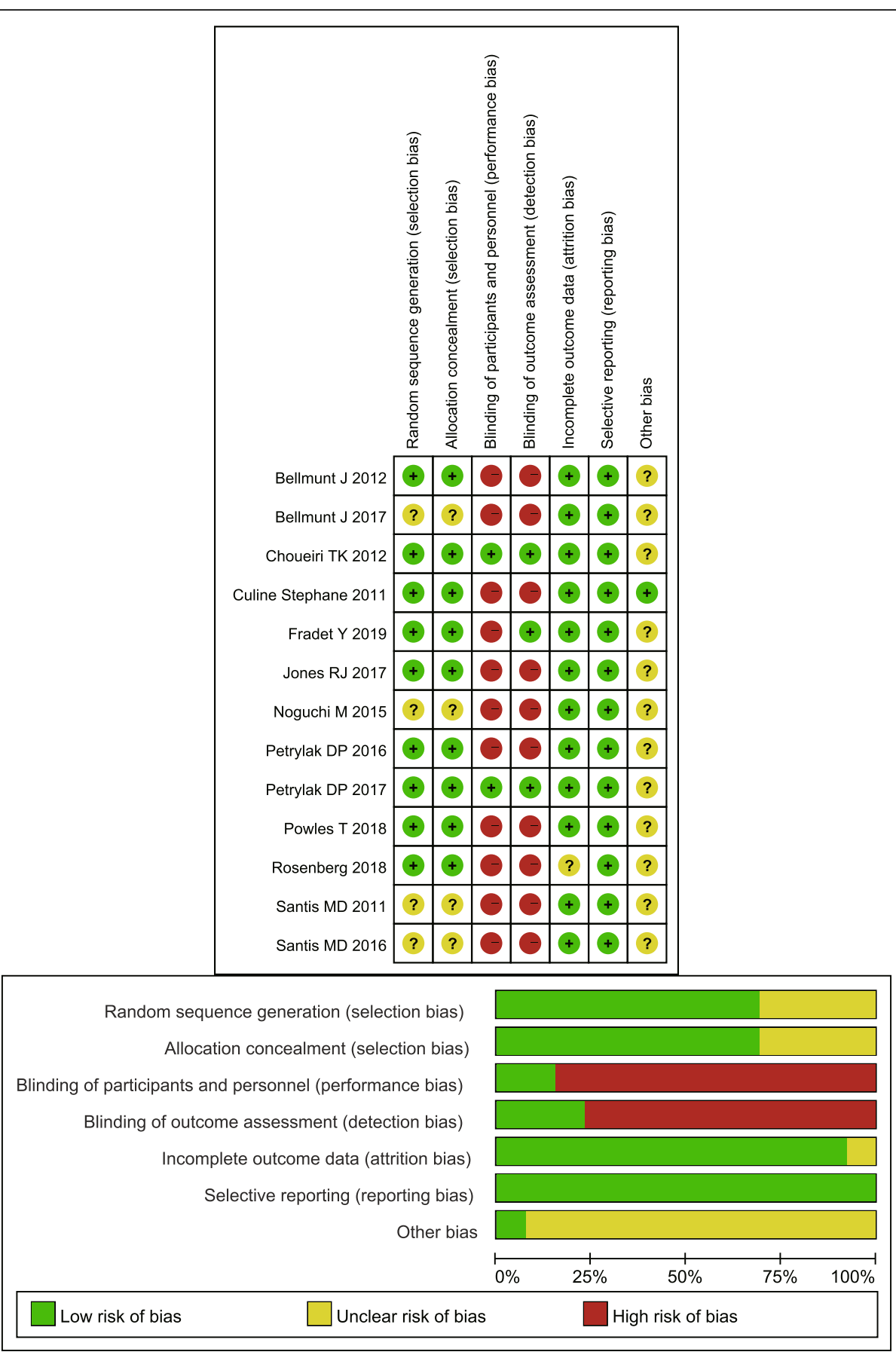

Fig. 2 Risk of bias of the included studies

In the OS results, there were eight comparisons on taxane, three on vinflunine, two on pembrolizumab and two on atezolizumab (Fig. 3b). In the consistency analysis, no local (Additional file 1: Figure S1) and global inconsistencies $(p=0.2732)$ were found. In network comparisons, atezolizumab was found to confer a significantly longer OS than pazopanib (ln HR: 0.49; 95\% CI: 0.03, 0.95) and taxane (ln HR: 0.24; 95\% CI: 0.03, 0.46).
Pembrolizumab was significantly superior to pazopanib (ln HR:-0.61; 95\% CI: - 1.07, - 0.15), taxane (ln HR: 0.36; 95\% CI: $0.15,0.57$ ), and vandetanib plus taxane (ln HR: 0.55; 95\% CI: 0.10, 1.01). Pembrolizumab (87.5\%), ramucirumab plus docetaxel (74.6\%), and atezolizumab (71.1\%) had a relative advantage in the SUCRA results (Table 3). For the ORR results, there were six comparisons on taxane and a comparison between ramucirumab 


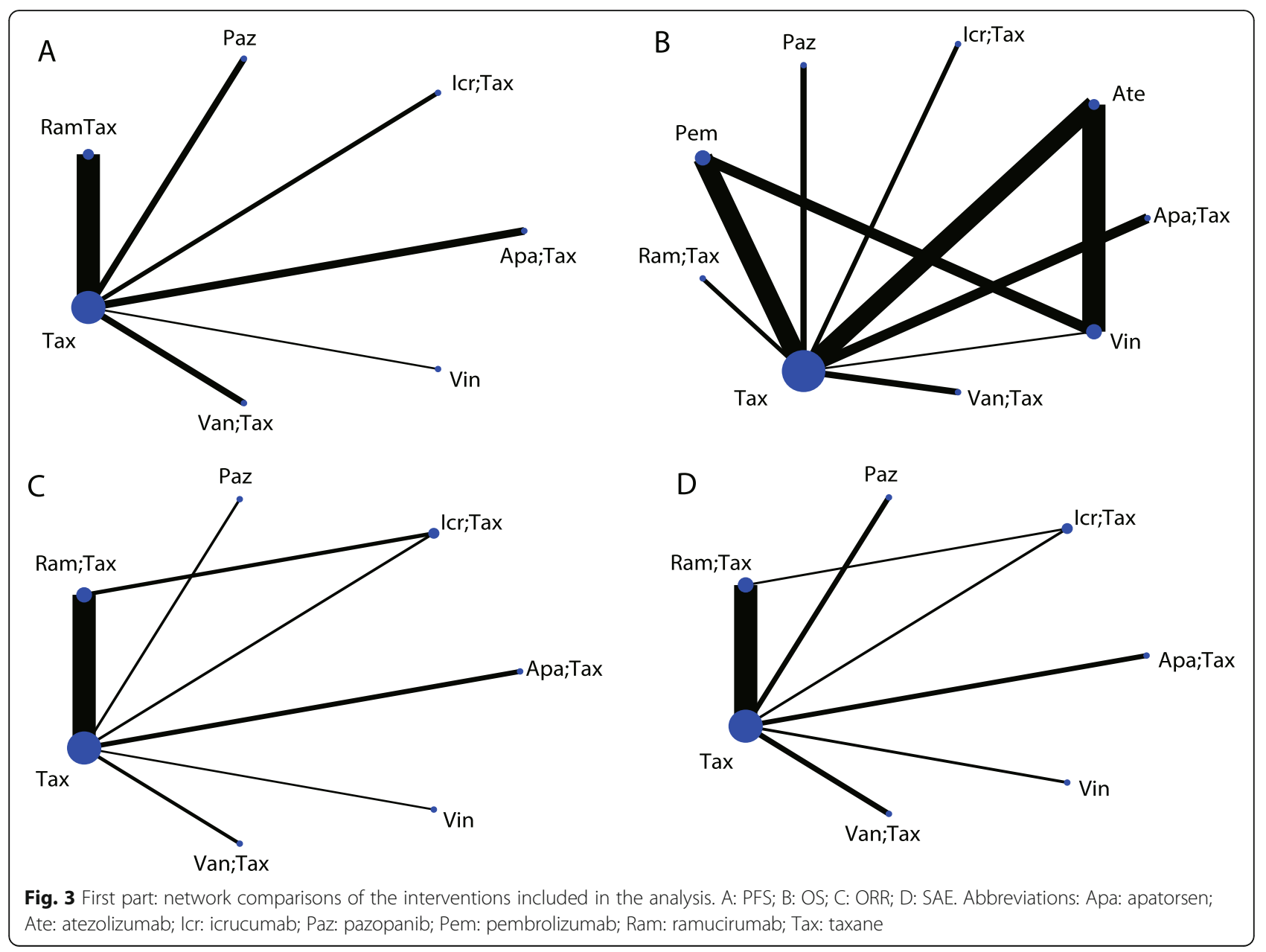

Table 2 The league table for PFS estimates interventions according to their relative effects in first part network analysis

\begin{tabular}{|c|c|c|c|c|c|c|}
\hline $\begin{array}{l}\text { Apatorsen+Taxane } \\
(50.9 \%)^{\mathrm{a}}\end{array}$ & & & & & & \\
\hline$-0.49(-1.90,0.93)$ & $\begin{array}{l}\text { Vinflunine } \\
(79 \%)\end{array}$ & & & & & \\
\hline $0.20(-1.09,1.49)$ & $\begin{array}{l}0.69(-0.73 \\
2.11)\end{array}$ & $\begin{array}{l}\text { Vandetanib+Taxane } \\
(36.3 \%)\end{array}$ & & & & \\
\hline $0.22(-0.68,1.13)$ & $\begin{array}{l}0.71(-0.38 \\
1.80)\end{array}$ & $0.02(-0.90,0.94)$ & Taxane (31.7\%) & & & \\
\hline$-0.35(-1.47,0.77)$ & $\begin{array}{l}0.14(-1.13 \\
1.41)\end{array}$ & $-0.55(-1.68,0.58)$ & $\begin{array}{l}-0.57(-1.23 \\
0.09)\end{array}$ & $\begin{array}{l}\text { Ramucirumab+Taxane } \\
(75.8 \%)\end{array}$ & & \\
\hline $0.31(-0.98,1.60)$ & $\begin{array}{l}0.80(-0.63 \\
2.22)\end{array}$ & $0.11(-1.19,1.41)$ & $\begin{array}{l}0.09(-0.83 \\
1.01)\end{array}$ & $0.66(-0.47,1.79)$ & $\begin{array}{l}\text { Pazopanib } \\
(30.4 \%)\end{array}$ & \\
\hline $0.08(-1.24,1.39)$ & $\begin{array}{l}0.56(-0.88 \\
2.01)\end{array}$ & $-0.13(-1.45,1.20)$ & $\begin{array}{l}-0.15(-1.10 \\
0.80)\end{array}$ & $0.42(-0.73,1.58)$ & $\begin{array}{l}-0.23(-1.56 \\
1.09)\end{array}$ & $\begin{array}{l}\text { Icrucumab+Taxane } \\
(45.9)\end{array}$ \\
\hline
\end{tabular}




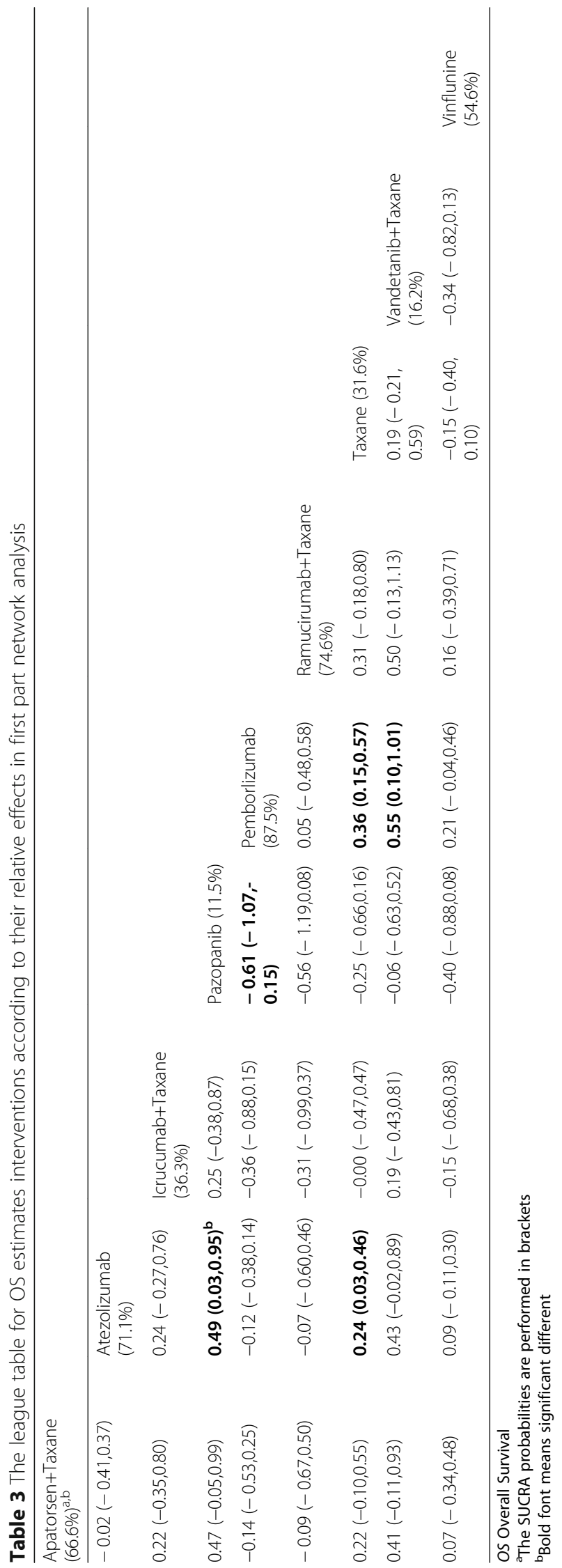


plus docetaxel and icrucumab plus docetaxel (Fig. 3c). There were no local (Additional file 2: Figure S2) or global inconsistencies $(p=0.4772)$. Pazopanib had less ORR events compared to ramucirumab plus docetaxel (ln OR: -1.97; 95\% CI: - 3.40, - 0.54) and vinflunine (ln OR: -2.27; 95\% CI: $-4.32,-0.21)$. Ramucirumab plus docetaxel had more events than taxane (ln OR: 0.76; 95\% CI: 0.30,1.21). According to the SUCRA ranks, vinflunine (84.4\%), ramucirumab plus docetaxel (82.4\%), and apatorsen plus docetaxel (64.9\%) have relative advantages (Table 4). There were no local (Additional file 3: Figure S3) or global inconsistencies $(p=0.0878)$ in the SAE results, and there were no significant differences in the network comparisons (Fig. 3d). Taxane had a relatively lower SAE frequency (79.8\%) (Table 5). In addition to atezolizumab and pembrolizumab, exploratory cluster analysis showed that vinflunine and ramucirumab plus docetaxel had a relatively high SUCRA rank (Fig. 4). There were no small-study effects in the first part of the network analysis (Fig. 5).

The second part of the network analysis compared atezolizumab, pembrolizumab, and ICC (Fig. 6a-d). For the PFS results, there were no significant differences (Additional file 5: Table S2). For the OS results, atezolizumab (ln HR: 0.16; 95\% CI: 0.01, 0.32) and pembrolizumab (ln HR: -0.36 ; $95 \%$ CI: $-0.55,-0.16)$ were both superior to ICC (Additional file 6: Table S3). The ORR results showed that pembrolizumab is superior to atezolizumab (ln OR: $-0.77 ; 95 \% \mathrm{CI}:-1.38,-0.16)$ and ICC (ln OR: -0.77 ; $95 \%$ CI: $-1.25,-0.29$ ) (Additional file 7: Table S4). For the SAE results, pembrolizumab had a lower frequency of SAEs than atezolizumab (ln OR: 1.41; 95\% CI: $0.91,1.90$ ) and ICC (ln OR: 1.63; 95\% CI: 1.21,2.04) (Additional file 8: Table S5). These results confirm the findings from the first part of the network analysis. Atezolizumab and pembrolizumab have advantages in OS. Pembrolizumab also has advantages in the ORR and SAE results. In the third part of the network analysis,
BSC was evaluated as a control (Fig. 6e-g). No significant difference was found in either the PFS or OS results (Additional file 9: Table S6:Additional file 10: Table S7).

The interventions and comparisons that did not enter the network analysis were assessed by traditional meta-analysis. In only the ORR comparison between PPV plus BSC and BSC (OR: 25.85; 95\% CI: 1.45, 461.43) was there a significant difference (Fig. 7). However, there was no objective response population in the BSC group in this study, so a large standard error value reduces the accuracy of the result.

\section{Discussion}

Platinum-based first-line chemotherapy is used to treat invasive-stage UC patients. When UC patients are cisplatin-ineligible or unfit, second-line treatment will be applied. However, the selection of second-line regimens in the clinic is still controversial. Conducting a comprehensive comparison among existing regimens and exploring more efficient and safe second-line treatments is still necessary. This work assessed the efficiency and safety of second-line therapy regimens for UC patients by network meta-analysis. The results showed that atezolizumab and pembrolizumab are superior to other treatments in only OS results, but no treatment confers a significant advantage in PFS results. Nevertheless, pembrolizumab still has relative advantages in ORR and SAE results. In addition to atezolizumab and pembrolizumab, exploratory cluster analysis showed that vinflunine and ramucirumab plus docetaxel had relatively high SUCRA ranks.

In a previous meta-analysis, immunotherapy, chemotherapy and antiangiogenesis were compared and analyzed. The results showed that immunotherapy, but not vinflunine, had more obvious benefits than taxanes regardless of PD-L1 status. Chemotherapy combined with vascular endothelial growth factor (VEGF) inhibitors did not significantly improve PFS or OS outcomes compared

Table 4 The league table for ORR estimates interventions according to their relative effects in first part network analysis

\begin{tabular}{|c|c|c|c|c|c|c|}
\hline $\begin{array}{l}\text { Apatorsen+Taxan } \\
(64.9 \%)^{a}\end{array}$ & & & & & & \\
\hline $\begin{array}{l}0.37(-1.08 \\
1.83)\end{array}$ & $\begin{array}{l}\text { Icrucumab+Taxane } \\
(46.8 \%)\end{array}$ & & & & & \\
\hline $1.66(-0.02,3.33)$ & $1.29(-0.44,3.01)$ & Pazopanib (6\%) & & & & \\
\hline $\begin{array}{l}-0.31(-1.40 \\
0.77)\end{array}$ & $-0.69(-1.72,0.35)$ & $\begin{array}{l}-1.97(-3.40,- \\
0.54)^{b}\end{array}$ & $\begin{array}{l}\text { Ramucirumab+Taxane } \\
(82.4 \%)\end{array}$ & & & \\
\hline $\begin{array}{l}0.44(-0.54 \\
1.43)\end{array}$ & $0.07(-1.00,1.14)$ & $-1.22(-2.57,0.14)$ & $0.76(0.30,1.21)$ & Taxane (41.5\%) & & \\
\hline $0.93(-0.60,2.46)$ & $0.55(-1.03,2.14)$ & $-0.73(-2.52,1.06)$ & $1.24(-0.01,2.50)$ & $\begin{array}{l}0.49(-0.68 \\
1.65)\end{array}$ & $\begin{array}{l}\text { Vandetanib+Taxane } \\
(24 \%)\end{array}$ & \\
\hline $\begin{array}{l}-0.61(-2.44 \\
1.22)\end{array}$ & $-0.98(-2.86,0.90)$ & $\begin{array}{l}-2.27(-4.32,- \\
0.21)\end{array}$ & $-0.29(-1.91,1.32)$ & $\begin{array}{l}-1.05(-2.59 \\
0.50)\end{array}$ & $-1.54(-3.47,0.40)$ & $\begin{array}{l}\text { Vinflunine } \\
(84.4 \%)\end{array}$ \\
\hline
\end{tabular}

ORR Objective response rate

aThe SUCRA probabilities are performed in brackets

bold font means significant different 
Table 5 The league table for SAE estimates interventions according to their relative effects in first part network analysis

\begin{tabular}{|c|c|c|c|c|c|c|}
\hline $\begin{array}{l}\text { Apatoren+Taxane } \\
(49.6 \%) \#\end{array}$ & & & & & & \\
\hline$-0.21(-2.02,1.61)$ & $\begin{array}{l}\text { Icrucumab+Taxane } \\
(38.5 \%)\end{array}$ & & & & & \\
\hline$-0.25(-2.00,1.51)$ & $-0.04(-1.85,1.77)$ & $\begin{array}{l}\text { Pazopanib } \\
(36.7 \%)\end{array}$ & & & & \\
\hline $0.18(-1.36,1.73)$ & $0.39(-0.98,1.76)$ & $\begin{array}{l}0.43(-1.11 \\
1.97)\end{array}$ & $\begin{array}{l}\text { Ramucirumab+Taxane } \\
(59.7 \%)\end{array}$ & & & \\
\hline $0.47(-0.77,1.71)$ & $0.68(-0.64,2.00)$ & $\begin{array}{l}0.72(-0.52 \\
1.96)\end{array}$ & $0.29(-0.63,1.21)$ & Taxane $(79.8 \%)$ & & \\
\hline$-0.50(-2.25,1.24)$ & $-0.29(-2.10,1.51)$ & $\begin{array}{l}-0.26(-2.00 \\
1.49)\end{array}$ & $-0.69(-2.22,0.85)$ & $\begin{array}{l}-0.98(-2.20 \\
0.25)\end{array}$ & $\begin{array}{l}\text { Vandetanib+Taxane } \\
(24.7 \%)\end{array}$ & \\
\hline $0.24(-1.62,2.11)$ & $0.45(-1.47,2.37)$ & $\begin{array}{l}0.49(-1.37 \\
2.35)\end{array}$ & $0.06(-1.61,1.73)$ & $\begin{array}{l}-0.23(-1.62 \\
1.16)\end{array}$ & $0.75(-1.11,2.60)$ & $\begin{array}{l}\text { Vinflunine } \\
(61.1 \%)\end{array}$ \\
\hline
\end{tabular}

SAE Severe adverse effect

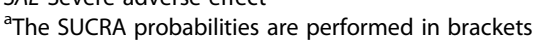

to chemotherapy alone [10]. These findings are similar to our results. Among the network comparisons, there was no significant advantage of intervention in PFS results, and in OS results, immunotherapy had a relative advantage.

Immune checkpoint inhibitors are a research hotspot in anticancer treatment [32]. Programmed death receptor 1 (PD-1)/programmed death ligand 1 (PD-L1) is a pair of negative costimulatory factors that play a key role in the tumor immune escape mechanism. PD-L1 can be expressed in tumor microenvironment cells and can inhibit the activation of $\mathrm{T}$ cells through binding to PD-1, which also weakens the entire immune system of patients [33-35]. Immune checkpoint therapy prevents PD-1/PD-L1 binding in tumors and restores the cytotoxicity of $\mathrm{T}$ cells [36].
Atezolizumab is a monoclonal antibody that specifically binds to PD-L1 with few serious side effects [37]. Pembrolizumab is a highly selective and humanized IgG4-k homologous PD-1 monoclonal antibody that is approved by the Food and Drug Administration of the United States for first-line AUC treatment [38]. Immune checkpoint inhibitors block the PD-1/PD-L1 connection between tumor microenvironment cells and $\mathrm{T}$ cells and improve the patient's immune system. Compared with cytotoxic drugs, the OS of patients is significantly improved with this method. This improvement may be achieved through the regulation of the immune system. However, there was no difference in PFS, which may indicate the indirect effects of checkpoint inhibitors.

In one included study, subgroup analysis showed that PD-L1-combined positive scores with a cutoff between 1

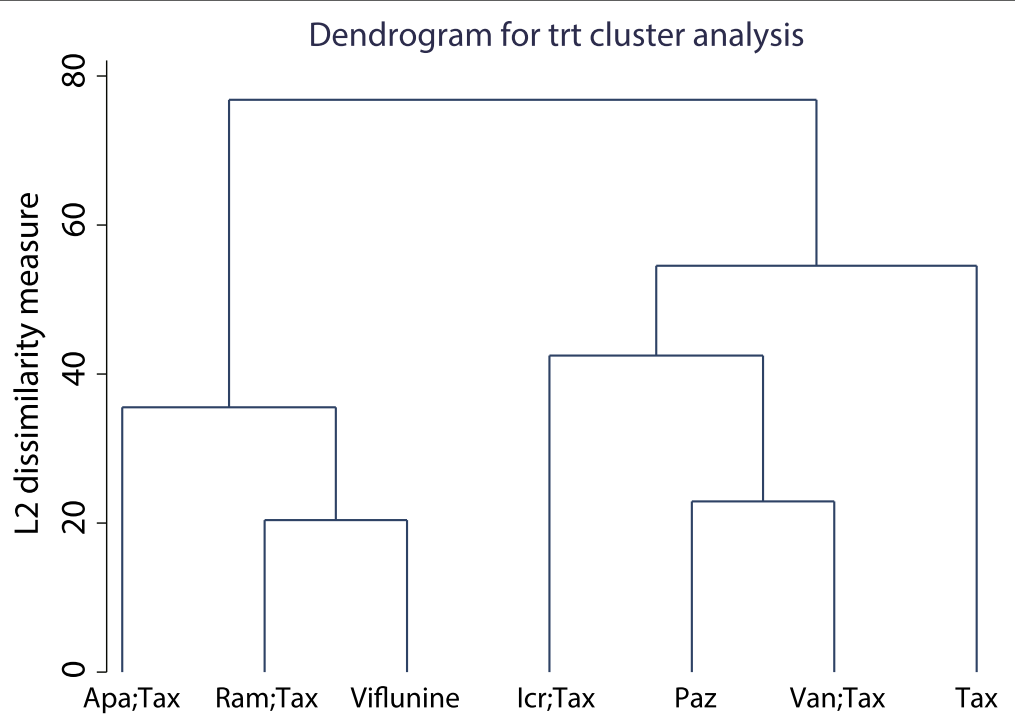

Fig. 4 Cluster analysis of the first part of the network analysis according to the SUCRA score. Abbreviations: Apa: apatorsen; Icr: icrucumab; Paz: pazopanib; Ram: ramucirumab; Tax: taxane 

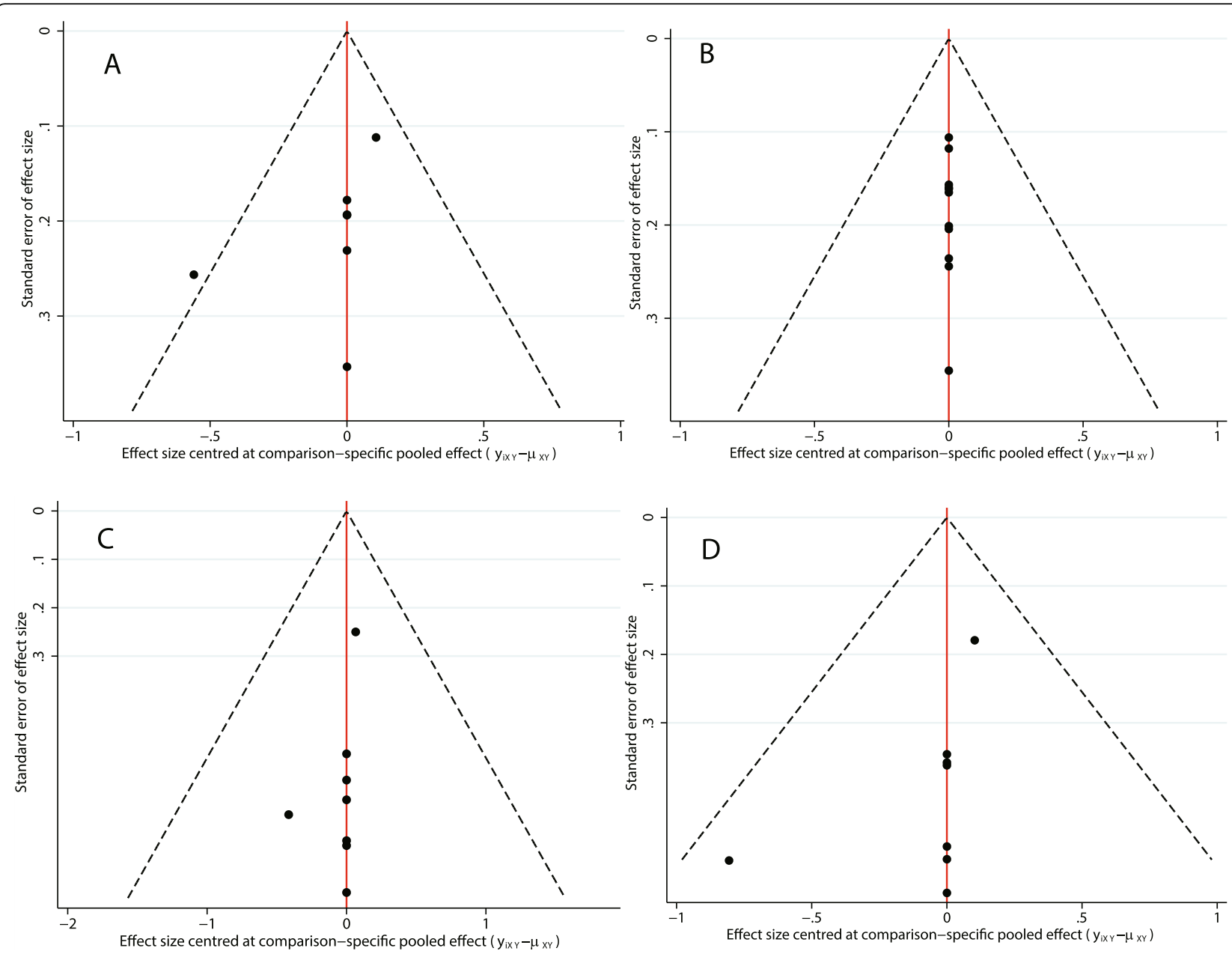

Fig. 5 Comparisons: adjusted funnel plots of the first part of the network meta-analysis. A: PFS; B: OS; C: ORR; D: SAE

and $10 \%$ could be predictive indicators that high positive-score patients have a longer OS period after checkpoint inhibitor application [31]. Unfortunately, there is still no PFS subgroup analysis report on the status of PD-L1 in this study. For other cancers, such as non-small cell lung cancer (NSCLC), an expression rate of PD-L1 greater than $50 \%$ can be used as reliable evidence for the use of immunological checkpoint drugs [39]. However, the IMvigor211 trial showed that in the PD-L1 expression rate in tumor-infiltrating immune cells in more than $5 \%$ of the population, atezolizumab did not provide significant benefits in patient survival $[11,20]$. It is possible that the expression of PD-L1 in tumors or immune cells plays a more important role in guiding the application of PD-1 inhibitors than that of PD-L1 inhibitors. However, this view still needs further confirmation. Nonetheless, the above research also provides a research direction for individual treatment in clinical treatment.

PPV is also an individual treatment for patients with an improved immune system [26]. Up to four of the 31 human leukocyte antigen (HLA) vaccines were selected and applied according to the HLA type and host immunity before vaccination. However, in our research, PPV plus BSC is superior to BSC in only the ORR results but not the OS and PFS results. Nevertheless, this is still a novel attempt at individualized precise immunotherapy. Applying PPVs more conveniently and the quantity production of PPVs are the main issues.

Ramucirumab is an antagonist of VEGF. A previous meta-analysis suggested that its combination with docetaxel did not improve PFS and OS [10]. In our network comparison, ramucirumab plus docetaxel still has the advantage of a high SUCRA ranking, but there was no significant difference. However, ramucirumab had a better therapeutic effect in other tumors compared with $\mathrm{UC}$, such as advanced gastric or esophagogastric junction adenocarcinoma and metastatic NSCLC [40-42]. In addition, antiangiogenic agents, such as icrucumab (targets vascular endothelial growth factor receptor 1, VEGFR1), pazopanib (VEGFR), and vandetanib (VEGFR3), also did not show obvious advantages. 


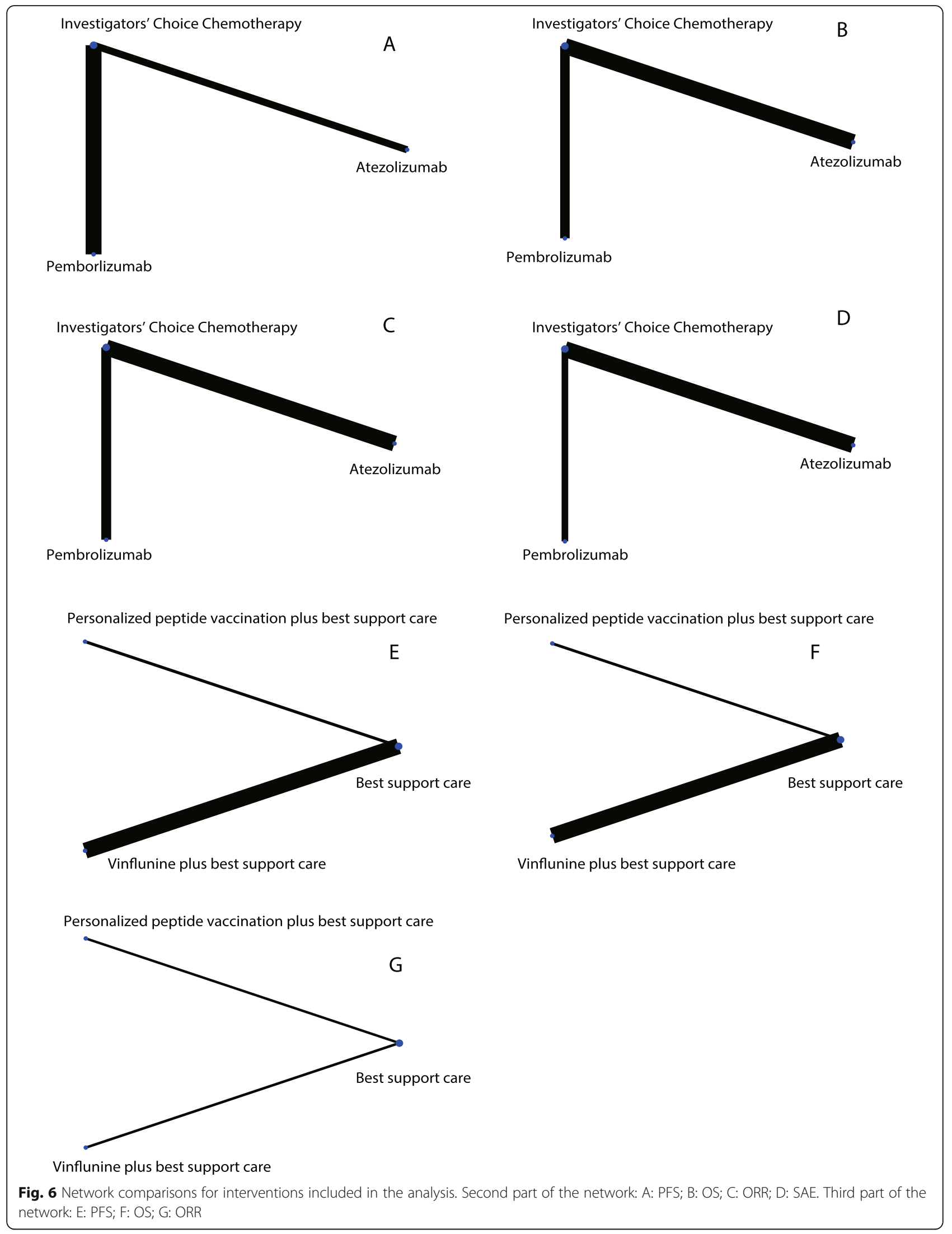




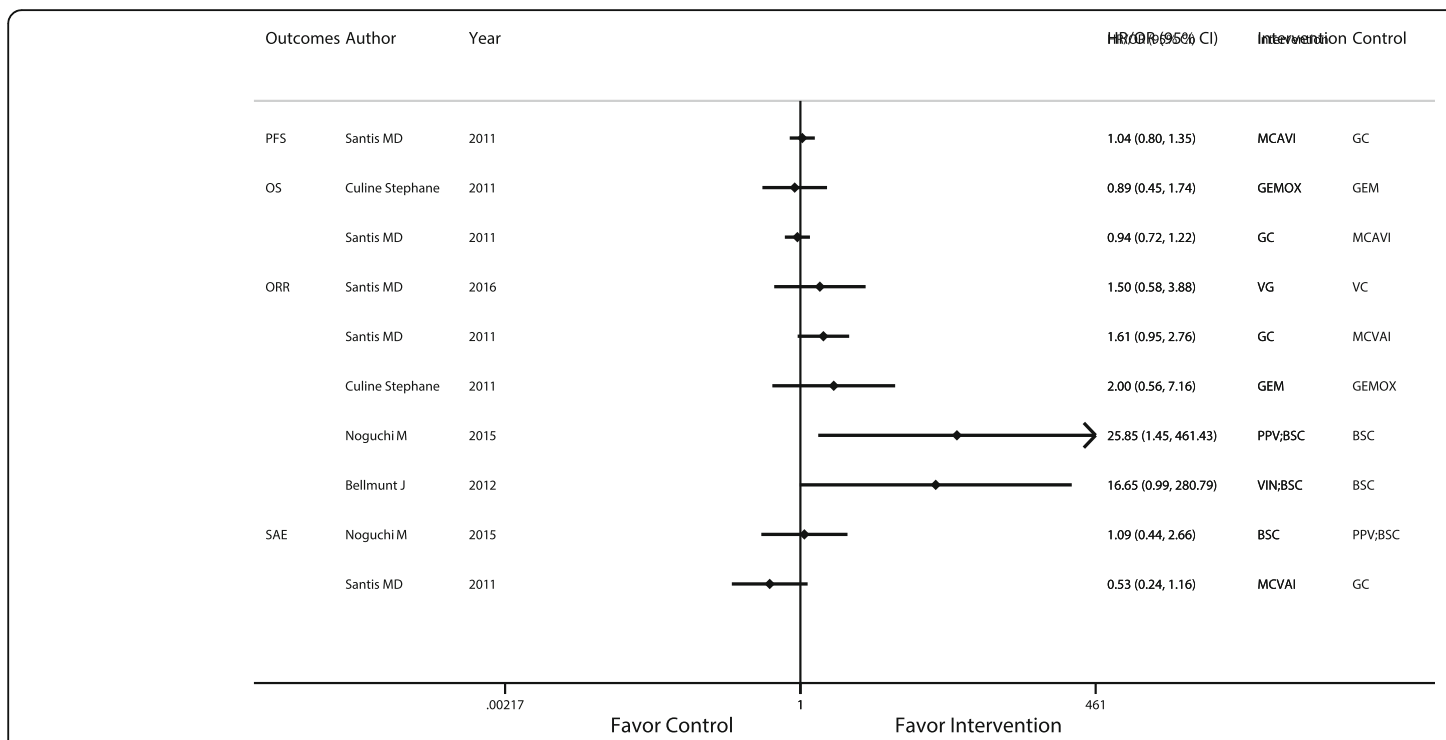

Fig. 7 Traditional meta-analysis of comparisons that were not included in the network meta-analysis. Abbreviations: BSC: Best support care; GC: Gemcitabine plus carboplatin; GEM: Gemcitabine; GEMOX: Gemcitabine plus oxaliplatin; MCAVI: Methotrexate plus carboplatin plus vinblastine; PPV: Personalized peptide vaccination; VC: Vinflunine plus Carboplatin; VG: Vinflunine plus Gemcitabine; VIN: Vinflunine

Antiangiogenesis therapy does not bring obvious survival benefits to UC patients, which indicates that blocking neovascularization does not affect the invasiveness of tumors. Likewise, systemic drug administration does not block the formation of neovascularization in UC, which has a relatively poor blood supply. At the superficial UC stage, intravesical perfusion can achieve a good therapeutic effect. Further research may not be limited to novel drug development but can improve effectiveness by changing the route of medication. For example, local urethral puncture injection with a cystoscope or even surface puncture injection under the guidance of radiography can efficiently reach the tumor microenvironment.

\section{Limitation}

Several limitations still exist. First, this study was conducted at the base trial level but not at the individual level. Second, the differences in patient characteristics between groups, such as between the cisplatin-ineligible and cisplatin-resistant patients, and the use of various ORR evaluation criteria are sources of heterogeneity in this study. Third, due to the absence of a common control, the network analysis was divided into three categories. Fourth, the impacts of drug dosage and the application period were not analyzed. Fifth, ICC and BSC interventions were selected for treatment according to the patients' condition and to investigate judgment, so heterogeneity exists. Sixth, taxanes were considered as one type drug in this study, including docetaxel, cabazitaxel, and paclitaxel. Seventh, this study will need to be updated when new drugs and clinical outcomes emerge.

\section{Conclusions}

At present, atezolizumab and pembrolizumab are superior to other treatments in only the OS results, but no treatment confers a significant advantage in PFS. Pembrolizumab still has relative advantages in ORR and SAE results compared to ICC.

\section{Supplementary information}

Supplementary information accompanies this paper at https://doi.org/10 1186/s12894-019-0560-7.

Additional file 1: Figure S1. Local inconsistency plot of loop-specific heterogeneity of the OS result in the first part of the network analysis.

Additional file 2: Figure S2. Local inconsistency plot of loop-specific heterogeneity of the ORR result in the first part of the network analysis.

Additional file 3: Figure S3. Local inconsistency plot of loop-specific heterogeneity of the SAE result in the first part of the network analysis.

Additional file 4: Table S1. The details of the search strategy in PubMed.

Additional file 5: Table S2. The league table for the PFS estimates of the interventions according to their relative effects in the second part of the network analysis.

Additional file 6: Table S3. The league table for the OS estimates of the interventions according to their relative effects in the second part of the network analysis.

Additional file 7: Table S4. The league table for the ORR estimates of the interventions according to their relative effects in second part network analysis.

Additional file 8: Table S5. The league table for the SAE estimates of the interventions according to their relative effects in the second part of the network analysis.

Additional file 9: Table S6. The league table for the PFS estimates of the interventions according to their relative effects in the third part of the network analysis. 
Additional file 10: Table S7. The leaque table for the OS estimates of the interventions according to their relative effects in the third part of the network analysis.

\section{Abbreviations}

Apa: apatorsen; Ate: atezolizumab; AUC: advanced urothelial carcinoma; BSC: best support care; Cls: confidence intervals; GC: gemcitabine plus cisplatin; GEM: gemcitabine; GEMOX: gemcitabine plus oxaliplatin; HLA: human leukocyte antigen; HRs: hazard ratios; ICC: investigator's choice chemotherapy; Icr: icrucumab; MCAVI: methotrexate plus carboplatin plus vinblastine; MIUC: muscle-invasive urothelial carcinoma; MVAC: methotrexate, vinblastine, doxorubicin, and cisplatin; NCl: National Cancer Institute; NSCLC: non-small cell lung cancer; ORR: objective response rate; ORs: odd ratios; OS: overall survival; Paz: pazopanib; PD-1: programmed death receptor 1; PD-L1; programmed death ligand 1; Pem: pembrolizumab; PFS: progression-free survival; PPV: personalized peptide vaccination; PRISMA: preferred reporting items for systematic reviews and meta-analyses; Ram: ramucirumab; RCTs: randomized controlled trials; SAE: severe adverse effect; SUCRA: surface under the cumulative ranking curve; Tax: taxane; UC: urothelial carcinoma; VC: vinflunine plus carboplatin; VEGF: vascular endothelial growth factor; VEGFR: vascular endothelial growth factor receptor; VG: vinflunine plus gemcitabine; VIN: vinflunine

\section{Acknowledgements}

None.

\section{Conflict of interest}

The authors declare that there is no conflict of interests regarding the publication of this article.

\section{Authors' contributions}

Study concept and design: HW; Literature research: KF and CK; Data acquisition: YJ and TC; Data analysis: GW; Statistical analysis: XS and TY; Manuscript preparation: HW; Manuscript editing: JL; Manuscript review: JL. All authors have approved the manuscript and agree with its submission.

\section{Authors' information}

Department of Urology, The Second Affiliated Hospital of Kunming Medical University, Kunming, Yunnan, 650101, PR China.

Huitao Wang, Jianhe Liu, Kewei Fang, Changxing Ke, Yongming Jiang, Guang Wang, Tongxin Yang, Tao Chen, Xin Shi.

\section{Funding}

No funds were received in support of this study.

\section{Availability of data and materials}

The datasets supporting the conclusions of this article are included within the article and its additional files.

\section{Ethics approval and consent to participate}

Not applicable.

\section{Consent for publication}

Not applicable.

\section{Competing interests}

The authors declare that there is no conflict of interests regarding the publication of this article.

\section{Received: 7 August 2019 Accepted: 15 November 2019}

\section{Published online: 02 December 2019}

\section{References}

1. Lin T, Liu Z, Liu L, et al. Prospective evaluation of fluorescence in situ hybridization for diagnosing urothelial carcinoma. Oncol Lett. 2017;13(5): 3928-34.

2. Niegisch G, Gerullis H, Lin SW, et al. A real-world data study to evaluate treatment patterns, clinical characteristics and survival outcomes for firstand second-line treatment in locally advanced and metastatic Urothelial Cancer patients in Germany. J Cancer. 2018;9(8):1337-48.
3. Nakagawa T, Taguchi S, Kanatani A, et al. Oncologic outcome of Metastasectomy for Urothelial carcinoma: who is the best candidate? Ann Surg Oncol. 2017;24(9):2794-800.

4. Wu XJ, Zhi Y, He P, et al. Comparison of single agent versus combined chemotherapy in previously treated patients with advanced urothelial carcinoma: a meta-analysis. Onco Targets Ther. 2016;9:1535-43 PMCID: 4801158.

5. Hsieh MC, Huang $\mathrm{CH}$, Chiang PH, Chen YY, Tang Y, Su YL. Tailored selection of first-line cisplatin-based chemotherapy in patients with metastatic urothelial carcinoma of bladder. J Cancer. 2016;7(10):1347-52 PMCID: 4934043.

6. Oing C, Rink M, Oechsle K, Seidel C, von Amsberg G, Bokemeyer C. Second line chemotherapy for advanced and metastatic Urothelial carcinoma: Vinflunine and beyond-a comprehensive review of the current literature. J Urol. 2016;195(2):254-63.

7. Zachos I, Konstantinopoulos PA, Tzortzis V, et al. Systemic therapy of metastatic bladder cancer in the molecular era: current status and future promise. Expert Opin Investig Drugs. 2010;19(7):875-87.

8. de Vos FY, de Wit R. Choosing chemotherapy in patients with advanced urothelial cell cancer who are unfit to receive cisplatin-based chemotherapy. Ther Adv Med Oncol. 2010;2(6):381-8.

9. Sella A, Kovel S. Combination of gemcitabine and carboplatin in urothelial cancer patients unfit for cisplatin due to impaired renal or cardiac function. Int Braz J Urol. 2012;38(1):49-56.

10. Ciccarese C, lacovelli R, Bria E, et al. Second-line therapy for metastatic urothelial carcinoma: defining the best treatment option among immunotherapy, chemotherapy, and antiangiogenic targeted therapies. A systematic review and meta-analysis. Semin Oncol. 2019;46(1):65-72.

11. Di Nunno V, De Luca E, Buttigliero C, et al. Immune-checkpoint inhibitors in previously treated patients with advanced or metastatic urothelial carcinoma: a systematic review and meta-analysis. Crit Rev Oncol Hematol. 2018;129:124-32.

12. Raggi D, Miceli R, Sonpavde G, et al. Second-line single-agent versus doublet chemotherapy as salvage therapy for metastatic urothelial cancer: a systematic review and meta-analysis. Ann Oncol. 2016;27(1):49-61.

13. Hutton B, Salanti G, Caldwell DM, et al. The PRISMA extension statement for reporting of systematic reviews incorporating network meta-analyses of health care interventions: checklist and explanations. Ann Intern Med. 2015; 162(11):777-84

14. Higgins JP, Altman DG, Gotzsche PC, et al. The Cochrane Collaboration's tool for assessing risk of bias in randomised trials. BMJ. 2011;343:d5928.

15. Greco T, Edefonti $V$, Biondi-Zoccai G, et al. A multilevel approach to network meta-analysis within a frequentist framework. Contemp Clin Trials. 2015;42:51-9.

16. Li D, Wang T, Shen S, et al. Effects of Fluroquinolones in newly diagnosed sputum-positive tuberculosis therapy: a systematic review and network meta-analysis. PLoS One. 2015;10(12):e0145066.

17. Trinquart L, Chatellier G, Ravaud P. Adjustment for reporting bias in network meta-analysis of antidepressant trials. BMC Med Res Methodol. 2012;12:150.

18. Fradet Y, Bellmunt J, Vaughn DJ, et al. Randomized phase III KEYNOTE-045 trial of pembrolizumab versus paclitaxel, docetaxel, or vinflunine in recurrent advanced urothelial cancer: results of $>2$ years of follow-up. Ann Oncol. 2019. https://doi.org/10.1093/annonc/mdz127 [Epub ahead of print].

19. Rosenberg JE, Hahn NM, Regan MM, et al. Apatorsen plus docetaxel versus docetaxel alone in platinum-resistant metastatic urothelial carcinoma (Borealis-2). Br J Cancer. 2018;118(11):1434-41.

20. Powles T, Duran I, van der Heijden MS, et al. Atezolizumab versus chemotherapy in patients with platinum-treated locally advanced or metastatic urothelial carcinoma (IMvigor211): a multicentre, open-label, phase 3 randomised controlled trial. Lancet. 2018;391(10122):748-57.

21. Petrylak DP, de Wit $R$, Chi KN, et al. Ramucirumab plus docetaxel versus placebo plus docetaxel in patients with locally advanced or metastatic urothelial carcinoma after platinum-based therapy (RANGE): a randomised, double-blind, phase 3 trial. Lancet. 2017;390(10109):2266-77.

22. Jones RJ, Hussain SA, Protheroe AS, et al. Randomized phase II study investigating Pazopanib versus weekly paclitaxel in relapsed or progressive Urothelial Cancer. J Clin Oncol. 2017;35(16):1770-7.

23. Bellmunt J, Kerst JM, Vazquez F, et al. A randomized phase II/III study of cabazitaxel versus vinflunine in metastatic or locally advanced transitional cell carcinoma of the urothelium (SECAVIN). Ann Oncol. 2017;28(7):1517-22. 
24. Petrylak DP, Tagawa ST, Kohli M, et al. Docetaxel as Monotherapy or combined with Ramucirumab or Icrucumab in second-line treatment for locally advanced or metastatic Urothelial carcinoma: an open-label, threearm, randomized controlled phase II trial. J Clin Oncol. 2016;34(13):1500-9.

25. De Santis M, Wiechno PJ, Bellmunt J, et al. Vinflunine-gemcitabine versus vinflunine-carboplatin as first-line chemotherapy in cisplatin-unfit patients with advanced urothelial carcinoma: results of an international randomized phase II trial (JASINT1). Ann Oncol. 2016;27(3):449-54.

26. Noguchi M, Matsumoto $\mathrm{K}$, Uemura $\mathrm{H}$, et al. An open-label, randomized phase II trial of personalized peptide vaccination in patients with bladder Cancer that progressed after platinum-based chemotherapy. Clin Cancer Res. 2016;22(1):54-60.

27. Bellmunt J, Fougeray R, Rosenberg JE, et al. Long-term survival results of a randomized phase III trial of vinflunine plus best supportive care versus best supportive care alone in advanced urothelial carcinoma patients after failure of platinum-based chemotherapy. Ann Oncol. 2013;24(6):1466-72.

28. Choueiri TK, Ross RW, Jacobus S, et al. Double-blind, randomized trial of docetaxel plus vandetanib versus docetaxel plus placebo in platinumpretreated metastatic urothelial cancer. J Clin Oncol. 2012;30(5):507-12.

29. De Santis $M$, Bellmunt J, Mead $G$, et al. Randomized phase $I / \| I$ trial assessing gemcitabine/carboplatin and methotrexate/carboplatin/vinblastine in patients with advanced urothelial cancer who are unfit for cisplatin-based chemotherapy: EORTC study 30986. J Clin Oncol. 2012;30(2):191-9.

30. Culine S, Flechon A, Guillot A, et al. Gemcitabine or gemcitabine plus oxaliplatin in the first-line treatment of patients with advanced transitional cell carcinoma of the urothelium unfit for cisplatin-based chemotherapy: a randomized phase 2 study of the French genitourinary tumor group (GETUG V01). Eur Urol. 2011;60(6):1251-7.

31. Bellmunt J, de Wit R, Vaughn DJ, et al. Pembrolizumab as second-line therapy for advanced Urothelial carcinoma. N Engl J Med. 2017;376(11):1015-26.

32. Xu C, Chen YP, Du XJ, et al. Comparative safety of immune checkpoint inhibitors in cancer: systematic review and network meta-analysis. BMJ. 2018;363:k4226.

33. Sato M, Tamura R, Tamura H, et al. Analysis of tumor angiogenesis and immune microenvironment in non-functional pituitary endocrine tumors. J Clin Med. 2019;8(5):E695

34. Jiang F, Yu W, Zeng F, et al. PD-1 high expression predicts lower local disease control in stage IV M0 nasopharyngeal carcinoma. BMC Cancer. 2019;19(1):503.

35. Incorvaia L, Badalamenti G, Rinaldi G, et al. Can the plasma PD-1 levels predict the presence and efficiency of tumor-infiltrating lymphocytes in patients with metastatic melanoma? Ther Adv Med Oncol. 2019;11: 1758835919848872.

36. Wei $Y$, Zhao Q, Gao Z, et al. The local immune landscape determines tumor PDL1 heterogeneity and sensitivity to therapy. J Clin Invest. 2019;129(8):3347-60.

37. Yang S, Zhang Z, Wang Q. Emerging therapies for small cell lung cancer. J Hematol Oncol. 2019;12(1):47.

38. Yu SS, Dorff TB, Ballas LK, Sadeghi S, Skinner EC, Quinn DI. Immunotherapy in urothelial cancer, part 1: T-cell checkpoint inhibition in advanced or metastatic disease. Clin Adv Hematol Oncol. 2017;15(6):466-77.

39. Kim J, Cho J, Lee MH, Lim JH. Relative efficacy of checkpoint inhibitors for advanced NSCLC according to programmed death-Ligand-1 expression: a systematic review and network meta-analysis. Sci Rep. 2018;8(1):11738.

40. Yamaguchi K, Fujitani K, Nagashima F, et al. Ramucirumab for the treatment of metastatic gastric or gastroesophageal junction adenocarcinoma following disease progression on first-line platinum- or fluoropyrimidinecontaining combination therapy in Japanese patients: a phase 2, open-label study. Gastric Cancer. 2018;21(6):1041-9.

41. Yoon HH, Bendell JC, Braiteh FS, et al. Ramucirumab combined with FOLFOX as front-line therapy for advanced esophageal, gastroesophageal junction, or gastric adenocarcinoma: a randomized, double-blind, multicenter phase II trial. Ann Oncol. 2016:27(12):2196-203.

42. Perol M, Ciuleanu TE, Arrieta O, et al. Quality of life results from the phase 3 REVEL randomized clinical trial of ramucirumab-plus-docetaxel versus placebo-plus-docetaxel in advanced/metastatic non-small cell lung cancer patients with progression after platinum-based chemotherapy. Lung Cancer. 2016:93:95-103.

\section{Publisher's Note}

Springer Nature remains neutral with regard to jurisdictional claims in published maps and institutional affiliations.

\section{Ready to submit your research? Choose BMC and benefit from:}

- fast, convenient online submission

- thorough peer review by experienced researchers in your field

- rapid publication on acceptance

- support for research data, including large and complex data types

- gold Open Access which fosters wider collaboration and increased citations

- maximum visibility for your research: over $100 \mathrm{M}$ website views per year

At BMC, research is always in progress.

Learn more biomedcentral.com/submissions 